\title{
Verrucous carcinoma of the oral mucosa: An epidemiological and follow-up study of patients treated with surgery in 5 last years
}

\author{
Alberto Candau-Alvarez ${ }^{1}$, Alicia Dean-Ferrer ${ }^{2}$, Francisco-Jesús Alamillos-Granados ${ }^{3}$, Susana Heredero- \\ Jung ${ }^{3}$, Blas García-García ${ }^{1}$, Juan-José Ruiz-Masera ${ }^{3}$, Rafael Arévalo-Arévalo ${ }^{3}$, Francisco Zafra-Camacho ${ }^{3}$, \\ Borja Valenzuela-Salas ${ }^{3}$
}

\footnotetext{
${ }^{1}$ Resident. Oral and Maxillofacial Surgery Department. Hospital Universitario "Reina Sofía", Córdoba (Spain)

${ }^{2}$ Head of Department. Oral and Maxillofacial Surgery Department. Hospital Universitario "Reina Sofía", Córdoba (Spain)

${ }^{3}$ Consultant. Oral and Maxillofacial Surgery Department. Hospital Universitario "Reina Sofía”, Córdoba (Spain)
}

Correspondence:

Avda/ República Argentina $n^{\circ} 24,3^{\circ}$

14004. Córdoba (Spain)

dr.candaualvarez@gmail.com

Received: 02/12/2013

Accepted: 09/03/2014

Candau-Alvarez A, Dean-Ferrer A, Alamillos-Granados FJ, HerederoJung S, García-García B, Ruiz-Masera JJ, Arévalo-Arévalo R, Zafra-Camacho F, Valenzuela-Salas B. Verrucous carcinoma of the oral mucosa: An epidemiological and follow-up study of patients treated with surgery in 5 last years. Med Oral Patol Oral Cir Bucal. 2014 Sep 1;19 (5):e506-11. http://www.medicinaoral.com/medoralfree01/v19i5/medoralv19i5p506.pdf

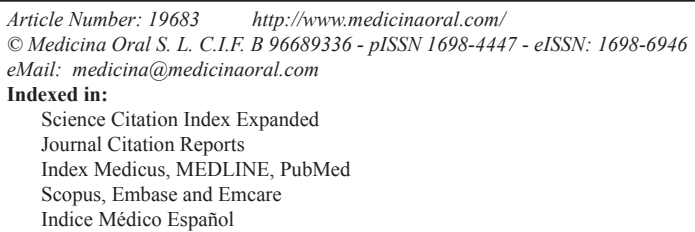

\begin{abstract}
Introduction: Oral Verrucous Carcinoma (OVC) is described apart of the Squamous Cell Carcinoma (SCC) due to its specific properties. The objective of our study is to show our series of cases of OVC and to compare with the SCC in terms of clinical manifestations, epidemiology, histopathology, treatment and follow-up.

Material and Methods: This is a retrospective study of all the OVC treated in our department between January2007 and December-2011. The analyzed variables were sex, age, localization in the oral cavity, histopathology, number of biopsies needed to diagnose OVC, TNM classification, treatment and recurrences during follow-up.

Results: Our sample was composed by $n=14$ patients, $57 \%$ female, with a mean age of 69.14 years. The most common localization was buccal mucosa $(n=5)$. Seven patients were diagnosed of OVC with the first biopsy. TNM classification was: pT1: 7 patients, pT2: 3 patients, pT3: 3 patients, pT4: 1 patient. No cervical metastases were observed either in cervical neck dissection or during the follow-up of the patients. The treatment was surgery with clinical resection margins up to $1 \mathrm{~cm}$ in all cases, followed by radiotherapy in selected cases. Only $\mathrm{n}=1$ patient (7.69\%) presented a recurrence after 34 months of follow-up. The overall survival rate was $92.85 \%$.

Conclusions: In our population, OVC represents the $6.16 \%$ of all oral cavity and oropharynx cancer, and is more frequent in female patients above 70 years old. It uses to rise over a previous lesion, and usually affects the buccal mucosa. In patients with high suspicious lesions, more than one biopsy may be needed to diagnose OVC. No patient showed cervical dissemination. In our experience, treatment based on local resection, without cervical neck dissection, could be a good option for these patients.
\end{abstract}

Key words: Verrucous carcinoma, squamous cell carcinoma, oral cancer, oral cavity, epidemiology, follow-up. 


\section{Introduction}

The Verrucous Carcinoma was described by LV Ackerman in 1948 (1) as an infrequent subtype of malignant disease which affects oral cavity. Usually, OVC presents a high tendency of local invasion, with a low tendency of dissemination, which varies depending on tumour size and evolution time (2), with a very low tendency to metastasize. Previous lesions as leucoplakias or eritroplakias, as well as Proliferative Verrucous Leucoplakia, are the sites where the OVC uses to arise from (3-5).

Its etiology is not well known, but smoking habit, alcohol consumption and betel nut chewing are proved causes. The role of the Human Papilomavirus in OVC oncogenesis is much less important than in the SCC oncogenesis (6-8).

Verrucous carcinoma usually debuts as an abnormal growth or as change in the consistency of a previous potentially malignant disorder of the oral cavity. All mucosal sites of the oral cavity can be affected. However, the rate of malignant transformation of a leukoplakia to an OVC is 20.81 times higher if they are located in the gingiva in comparison with the tongue (9).

Histopathologically, it frequently shows aneuploidy (10), which can be shown in conventional exfoliative cytology biopsies, which can be used as a marker of progression from potentially malignant disorder of the oral cavity to an OVC (Fig. 1).

Surgery is the best treatment. Although an optimal disease control can be achieved by surgery only, frequent revision is mandatory due to the increased risk of second tumours (11).

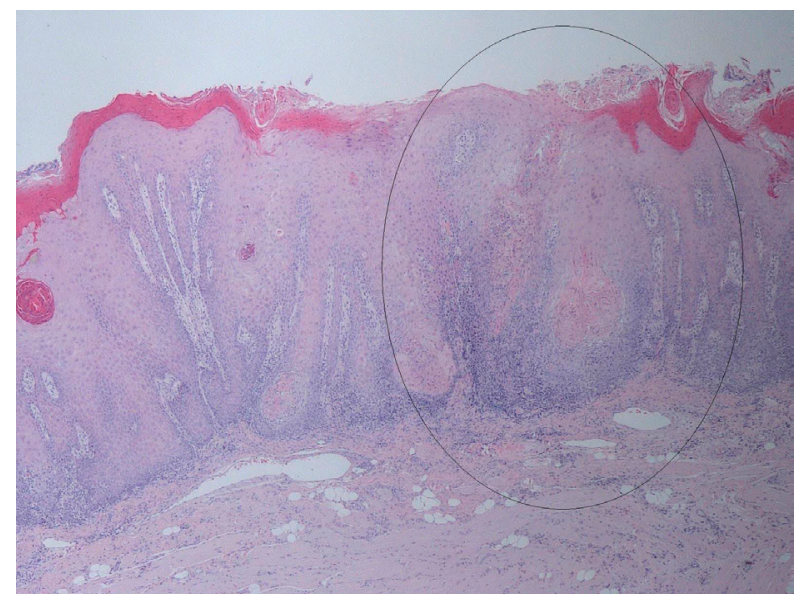

Fig. 1. General histopathological characteristics of the excised specimens revealed acanthosis, papillomatosis, and hyperkeratosis of the epithelium of the lesion, continuing with characteristics of healthy mucosa. Squamous epithelial cell composition of the tumors did not give a definite atypical character, but showed blunt rete processes toward the subepithelial area. Lymphocyte infiltration was noted in the periphery of the tumor islands. Hematoxylin-Eosin stain (H-E) 2x.
Our objective is to show our series of OVC patients, treated at our department, and to compare with the SCC in terms of clinical manifestations, epidemiology, histopathology, treatment and follow-up.

\section{Material and Methods}

We designed a descriptive and retrospective epidemiological study of patients diagnosed of OVC and treated by surgery in our institution between January/2007 and December/2011.

Between those years, we collected a total of 14 OVC patients, among $n=227$ patients diagnosed of SCC of the oral cavity, which met the following Inclusion Criteria: pathological confirmation of OVC of the biopsied specimen of the resected tumor, surgical treatment and follow-up during more than 6 months. We excluded all patients who did not fit the inclusion criteria.

The analyzed variables were: sex, age, localization in the oral cavity, histopathology, number of biopsies needed to diagnose OVC, TNM classification (based on American Joint Committee on Cancer, $7^{\text {th }}$ edition), treatment given and recurrences during follow-up. The statistical descriptive analysis was done using the SPSS v17.0.

\section{Results}

In our sample, $57 \%(\mathrm{n}=8)$ were woman, and $43 \%(\mathrm{n}=6)$ were males. The mean age was 69.14 years (range 8446). The most frequent localization was buccal mucosa ( $\mathrm{n}=5$ patients), followed by lip-commissure $(\mathrm{n}=3)$, gingiva $(\mathrm{n}=3)$, tongue $(\mathrm{n}=2)$ and hard palate $(\mathrm{n}=1)$. In $\mathrm{n}=2$ patients histopathological study revealed "hybrid verrucous carcinoma". More epidemiological data are shown in table 1 . Half of the patients $(\mathrm{n}=7)$ needed more than one biopsy to establish OVC diagnosis. Those previous biopsies were informed as epithelial hyperplasia $(\mathrm{n}=3)$, parakeratosis with acantosis $(n=2)$, simple keratosis $(n=2)$ and verrucous hyperplasia $(\mathrm{n}=1)$. The TNM classification was pT1 (n=7), pT2 (n=3), pT3 $(n=3)$, and pT4 $(n=1)$. The treatment in all cases was local resection with clinical margins above $1 \mathrm{~cm}$. In $\mathrm{n}=3$ cases, a supraomohyoid cervical neck dissection were performed, and a radical neck dissection in $\mathrm{n}=1$ case. The mean histopathological distance to deep resection margin was $5.35 \mathrm{~mm}$ (median $5.5 \mathrm{~mm}$ ). Radiotherapy was administered to $\mathrm{T} 3$ and $\mathrm{T} 4$ patients and in patient \#4 due to close histopathological margin $(1 \mathrm{~mm})$. The mean follow-up was 24.76 months (range 6-53 months). Data about surgery and follow-up are shown in table 2. Only $n=1$ patient (\#6) died due a massive hemorrhage in his early postoperatory period, and was not considered to perform follow-up and recurrence rate statistics. The recurrence rate was $7.69 \%$ $(n=1 / 13$ patients), which occurred after 34 months. The overall survival rate was $92.85 \%$ (13/14 patients). 
Table 1. Epidemiological description of the Oral Verrucous Carcinoma.

\begin{tabular}{|c|c|c|c|c|c|}
\hline Patient & Sex & $\begin{array}{c}\text { Age at } \\
\text { diagnosis }\end{array}$ & Localization & TNM & Histology \\
\hline 1 & Male & 79 & Buccal Mucosa & T2N0M0 & Pure OVC \\
\hline 2 & Female & 52 & Tongue & T2N0M0 & Pure OVC \\
\hline 3 & Female & 77 & Buccal Mucosa & T3N0M0 & Pure OVC \\
\hline 4 & Female & 71 & Gingiva & T2N0M0 & Pure OVC \\
\hline 5 & Male & 84 & Lower lip & T1N0M0 & Pure OVC \\
\hline 6 & Male & 74 & Gingiva & T1N0M0 & Pure OVC \\
\hline 7 & Male & 75 & Hard Palate & T1N0M0 & Pure OVC \\
\hline 8 & Female & 62 & Oral Commissure & T1N0M0 & Pure OVC \\
\hline 9 & Male & 46 & Oral Commissure & T1N0M0 & Pure OVC \\
\hline 10 & Male & 80 & Buccal Mucosa & T3N0M0 & Pure OVC \\
\hline 11 & Female & 72 & Buccal Mucosa & T1N0M0 & Pure OVC \\
\hline 12 & Female & 59 & Tongue & T1N0M0 & Pure OVC \\
\hline 13 & Female & 65 & Gingiva & T4N0M0 & Hybrid OVC \\
\hline 14 & Female & 72 & Buccal Mucosa & T3N0M0 & Hybrid OVC \\
\hline
\end{tabular}

Table 2. Treatment and Follow-Up of the Oral Verrucous Carcinoma patients. SOND: Supra-Omohyoid Neck Dissection. RND: Radical Neck Dissection.

\begin{tabular}{|c|c|c|c|c|}
\hline Patient & Surgery & $\begin{array}{c}\text { Closest distance to } \\
\text { tumour }(\mathbf{m m})\end{array}$ & $\begin{array}{c}\text { Follow-up period } \\
\text { (months) }\end{array}$ & Recurrence \\
\hline 1 & Local resection & 3 & 53 & NO \\
\hline 2 & Local resection & 3 & 51 & NO \\
\hline 3 & Local resection and SOND & 5 & 40 & NO \\
\hline 4 & Local resection & 1 & 38 & NO \\
\hline 5 & Local resection & 11 & 31 & NO \\
\hline 6 & Local resection & 4 & 1 (Died at early postop) & NOT VALID \\
\hline 7 & Local resection & 2 & 18 & NO \\
\hline 8 & Local resection & 6 & 13 & NO \\
\hline 9 & Local resection & 3 & 12 & NO \\
\hline 10 & Local resection and SOND & 9 & 9 & NO \\
\hline 11 & Local resection & 6 & 7 & NO \\
\hline 12 & Local resection & 8 & 6 & NO \\
\hline 13 & Local resection and RND & 6 & 34 & NO \\
\hline 14 & Local resection and SOND & 8 & YES \\
\hline
\end{tabular}

\section{Discussion}

The prevalence of OVC for total carcinomas affecting the oral cavity and oropharynx is low, and as revised in Rekha et al. (12), is between $2-12 \%$. In our series, verrucous carcinoma of the oral cavity, with respect to all patients with oral cavity cancer, represents the $6.16 \%$, being in consonance with the reviewed literature.

Published series on Asian patients, reflect its greater incidence in men with prevalence as high as $77.4 \%$ (13) and $94.9 \%$ (14). This seems to be explained by consumer culture of betel nut and tobacco chewing. To the best of our known, no previous studies reflects the gender tendency of OVC in Spanish Caucasian population. In our sample, $57 \%$ were women, which can be in consonant with a population without tobacco chewing habits. Numerous studies (12-15) indicate that OVC primarily affects patients between 40 and 60 . The mean age at diagnosis in our patients was 69.14 years on average (median 71.5 years), which is almost $10-15$ years later in our series than in the literature. The earlier affectation in these patients may be due, in the opinion of the authors, to an early onset in the consumption of carcinogens such as betel nut.

The involvement of buccal mucosa appears in several articles as the most common (12-14), as well as in our study (Fig. 2). Other authors have reported a greater in- 


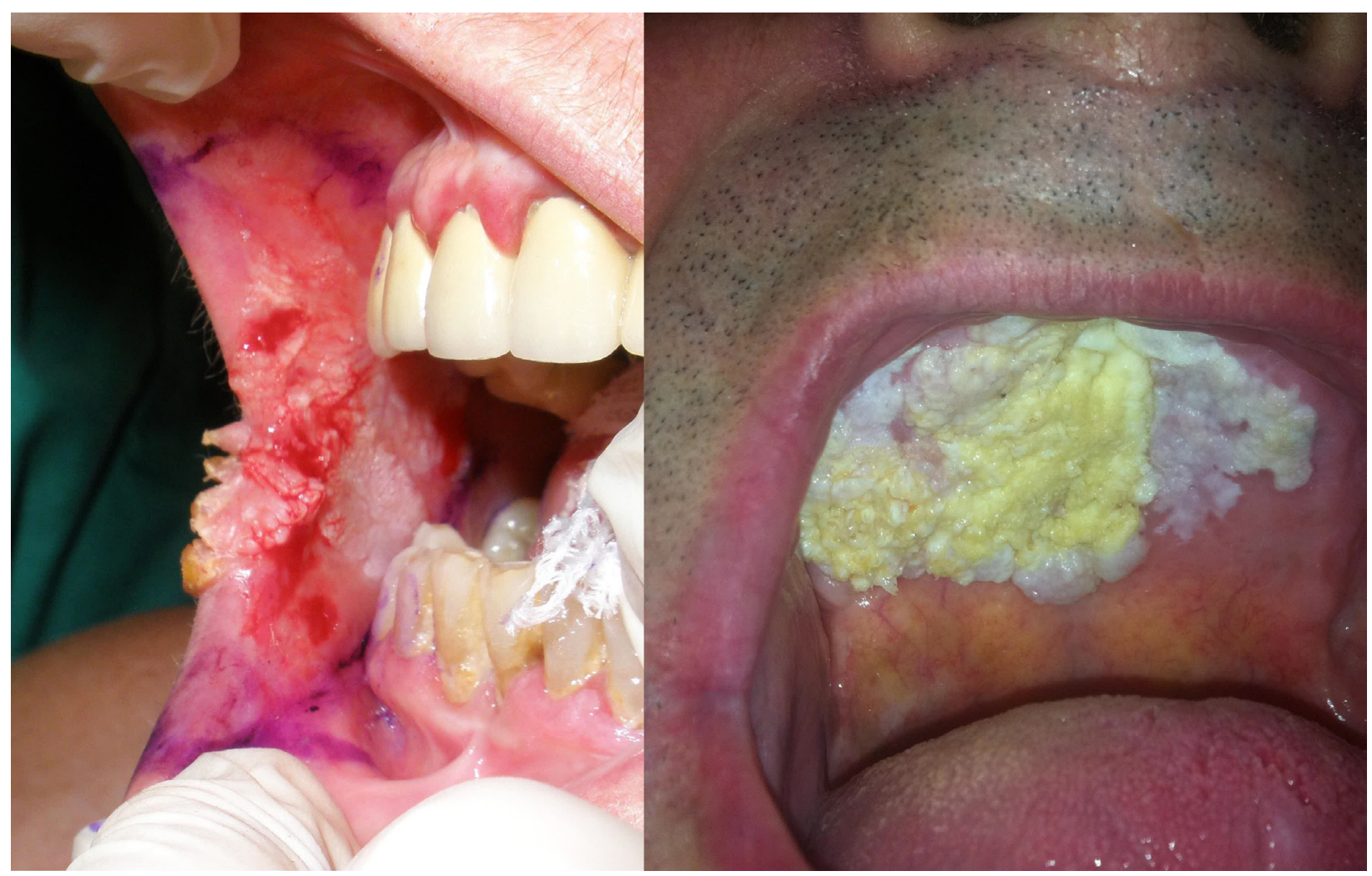

Fig. 2. Different localizations of OVC. Left: Buccal mucosa (patient \#11). Right: Hard Palate (patient \#7).

volvement of the lower lip $(15,16)$, alveolar ridge and gingiva $(3,17)$. The presence of a previous leukoplakia is also a constant $(2-5,12,13)$. Some authors report diagnoses like verrucous leukoplakia (17) or verrucous hyperplasia (18) in biopsies of long standing leukoplakia in which an OVC appeared later. In our study we found $\mathrm{n}=7$ OVC patients with previous verrucous leukoplakia in which subsequent biopsies were performed, with histopathological diagnoses similar to those described before. All our patients were treated by surgery. Local resection with 1 centimeter of clinical margin is considered by many authors $(19,20)$ as the treatment of choice for verrucous carcinoma. Although clinical margins were even greater than $1 \mathrm{~cm}$, due to tissue retraction, histological margins were closer to the tumor. However, histological margins above $5 \mathrm{~mm}$ were considered sufficient to not increase the risk of local recurrence (21). In patient \#4, due to its closest free margin $(1 \mathrm{~mm})$ and the impossibility to increase resection margins in a second surgery, received postoperative radiotherapy.

The need for a cervical dissection is also controversial. Case series published over the years agree that the OVC tends to grow locally but not to cause ganglionar spread $(22,23)$. However, there are few published papers that refer of distant metastases as in the orbit (24) and axillary lymph nodes (25). Thereby, cervical dissection should not be indicated in all cases of OVC. Because of an initial biopsy of SCC in patients \#3 and \#10, a Supraomohyoid Neck Dissection was performed due to the size of the tumor (T3 and T4), which were informed as negative (pN0) in both cases. Also T3 and T4 patients received radiotherapy after surgery.

We have identified an important diagnostic problem, which is the differentiation between "pure" OVC and "hybrid" OVC, which has foci of squamous cell carcinoma. The hybrid OVC can be up to $20 \%$ of diagnosed OVC, and behaves like squamous cell carcinomas regarding to their metastatic spreading tendency (26). In these cases, performing a cervical neck dissection is recommended, as if it were a squamous cell carcinoma. In our series, in $\mathrm{n}=2$ patients (patients $\# 13$ and \#14), the histopathological study was informed as hybrid OVC, while the rest were pure OVC. One of these 2 patients (patient \#13) was diagnosed preoperatively of hybrid OVC, and due both to this diagnosis and to the size of the tumor (T4), underwent a Modified Radical Neck Dissection type III (preserving the Internal Jugular Vein, the Spinal Nerve and the Sternocleidomastoid Muscle) which was informed as negative (pN0). The other patient (case \#14) had an initial biopsy of OVC, and underwent local wide resection, and after the histopathological study was reclassified as a hybrid OVC, and secondary performed a Supraomohyoid Neck Dissection which was informed as negative (pN0). Neither 
cases of hybrid OVC exhibited metastasis along the follow-up (6 and 34 months, respectively). Also, as befits a pure OVC (20), no patient had cervical lymph node metastases, either in previous imaging studies, or in the histopathological studies in those who underwent prophylactic neck dissection.

During the follow-up of our patients, only one patient had a local tumor recurrence 34 months after surgery in the buccal mucosa, biopsied as OVC again, and treated by surgery. No second tumors were found. Since the follow-up period was uneven for all patients, we can not state the recurrence rate at 5 years. Because the average follow-up was close to 2 years, we can say that the recurrence rate at 2 years of follow-up stood at $7.69 \%$. The long-term follow-up studies of OVC patients refer highly variable recurrence rates between 0 and $66.7 \%$ at 5 years $(13,15,19)$, which mostly depend on the type of treatment that has been given. Overall survival of the series was $92.85 \%$ (13/14 cases) for the follow-up period described above. Survival of patients with OVC to 5 years is between $93.65 \%$ (20) and $94.7 \%$ (19).

The most relevant limitation found in this article is the small size of the registered sample. Because our institution gives assistance to a population of a small city, the volume of oncological patients treated could be smaller than those that appear in other published series. Although $n=14$ patients represent a small sample, the prevalence of OVC among all SCC or the oral cavity in our series is similar to those published and referenced above. That is why we consider our sample as representative.

\section{Conclusion}

Verrucous carcinoma in our series appears in patients around 70 years, usually on a previous injury, often affecting the buccal mucosa. In patients with suspicious lesions more than one biopsy to diagnose a verrucous carcinoma may be needed. No patient had cervical lymph node involvement. Local resection with at least $5 \mathrm{~mm}$ of histological margin, without prophylactic neck dissection allows local control of the disease with recurrence rates of $7.69 \%$ at 2 years. Overall survival rate in our series was $92.85 \%$.

\section{References}

1. Steffen C. The man behind the eponym: Lauren V. Ackerman and verrucous carcinoma of Ackerman. Am J Dermatopathol. 2004;26:334-41.

2. Liu W, Shen XM, Liu Y, Li J, Zhou ZT, Wang LZ. Malignant transformation of oral verrucous leukoplakia: a clinicopathologic study of 53 cases. J Oral Pathol Med. 2011;40:312-6.

3. Bagan JV, Jiménez-Soriano Y, Diaz-Fernandez JM, MurilloCortés J, Sanchis-Bielsa JM, Poveda-Roda R, et al. Malignant transformation of proliferative verrucous leukoplakia to oral squamous cell carcinoma: A series of 55 cases. Oral Oncol. 2011;47:732-5.

4. Mete O, Keskin Y, Hafiz G, Kayhan KB, Unur M. Oral proliferative verrucous leukoplakia: Underdiagnosed oral precursor lesion that requires retrospective clinicopathological correlation. Dermatol Online J. 2010;16:6.

5. Bagan J, Scully C, Jimenez Y, Martorell M. Proliferative verrucous leukoplakia: a concise update. Oral Dis. 2010;16:328-32.

6. Saghravanian N, Ghazvini K, Babakoohi S, Firooz A, Mohtasham N. Low prevalence of high risk genotypes of human papilloma virus in normal oral mucosa, oral leukoplakia and verrucous carcinoma. Acta Odontol Scand. 2011;69:406-9.

7. Lin HP, Wang YP, Chiang CP. Expression of p53, MDM2, p21, heat shock protein 70, and HPV 16/18 E6 proteins in oral verrucous carcinoma and oral verrucous hyperplasia. Head Neck. 2011;33:334-40.

8. Yamakawa-Kakuta Y, Kawamata H, Doi Y, Fujimori T, Imai Y. Does the expression of HPV16/18 E6/E7 in head and neck squamous cell carcinomas relate to their clinicopathological characteristics?. Int J Oncol. 2009;35:983-8.

9. Alkan A, Bulut E, Gunhan O, Ozden B. Oral verrucous carcinoma: a study of 12 cases. Eur J Dent. 2010;4:202-7.

10. Maraki D, Boecking A, Pomjanski N, Megahed M, Becker J. Verrucous carcinoma of the buccal mucosa: histopathological, cytological and DNA-cytometric features. J Oral Pathol Med. 2006;35:633-5

11. Liao CT, Kang CJ, Chang JT, Wang HM, Ng SH, Hsueh C, et al. Survival of second and multiple primary tumors in patients with oral cavity squamous cell carcinoma in the betel quid chewing area. Oral Oncol. 2007;43:811-9.

12. Rekha KP, Angadi PV. Verrucous carcinoma of the oral cavity: a clinico-pathologic appraisal of 133 cases in Indians. Oral Maxillofac Surg. 2010;14:211-8.

13. Walvekar RR, Chaukar DA, Deshpande MS, Pai PS, Chaturvedi P, Kakade A, et al. Verrucous carcinoma of the oral cavity: A clinical and pathological study of 101 cases. Oral Oncol. 2009;45:47-51.

14. Huang TT, Hsu LP, Hsu YH, Chen PR. Surgical outcome in patients with oral verrucous carcinoma: long-term follow-up in an endemic betel quid chewing area. ORL J Otorhinolaryngol Relat Spec. 2009;71:323-8.

15. Oliveira DT, de Moraes RV, Fiamengui Filho JF, Fanton Neto J, Landman G, Kowalski LP. Oral verrucous carcinoma: a retrospective study in São Paulo Region, Brazil. Clin Oral Invest. 2006;10:205-9. 16. Zhu LK, Ding YW, Liu W, Zhou YM, Shi LJ, Zhou ZT. A clinicopathological study on verrucous hyperplasia and verrucous carcinoma of the oral mucosa. J Oral Pathol Med. 2012;41:131-5.

17. Gandolfo S, Castellani R, Pentenero M. Proliferative verrucous leukoplakia: a potentially malignant disorder involving periodontal sites. J Periodontol. 2009;80:274-81.

18. Wang YP, Chen HM, Kuo RC, Yu CH, Sun A, Liu BY, et al. Oral verrucous hyperplasia: histologic classification, prognosis, and clinical implications. J Oral Pathol Med. 2009;38:651-6.

19. Kang CJ, Chang JT, Chen TM, Chen IH, Liao CT. Surgical Treatment of Oral Verrucous Carcinoma. Chang Gung Med J. 2003;26:807-812.

20. Arduino PG, Carrozzo M, Pagano M, Gandolfo S, Broccoletti R. Verrucous oral carcinoma: clinical findings and treatment outcomes in 74 patients in Northwest Italy. Minerva Stomatol. 2008;57:335-9.

21. Jerjes W, Upile T, Petrie A, Riskalla A, Hamdoon Z, Vourvachis $\mathrm{M}$, et al. Clinicopathological parameters, recurrence, locoregional and distant metastasis in 115 T1-T2 oral squamous cell carcinoma patients. Head Neck Oncol. 2010;2:9.

22. Ogawa A, Fukuta Y, Nakajima T, Kanno SM, Obara A, Nakamura K, et al. Treatment results of oral verrucous carcinoma and its biological behavior. Oral Oncol. 2004;40:793-7.

23. Godlewska-Zoładkowska K, Olszewska E, Chodynicki S, Miasko A, Chyczewski L. Verrucous carcinoma-histological and molecular analysis. Otolaryngol Pol. 2003;57:793-7.

24. Asproudis I, Gorezis S, Aspiotis M, Tsanou E, Kitsiou E, Merminga E, et al. Orbital metastasis from verrucous carcinoma of the oral cavity: case report and review of the literature. In Vivo. 2007;21:909-12.

25. Gouvêa AF, Moreira AE, Reis RR, de Almeida OP, Lopes MA. Proliferative verrucous leukoplakia, squamous cell carcinoma and 
axillary metastasis. Med Oral Patol Oral Cir Bucal. 2010;15:e704-8. 26. Kolokythas A, Rogers TM, Miloro M. Hybrid verrucous squamous carcinoma of the oral cavity: treatment considerations based on a critical review of the literature. J Oral Maxillofac Surg. 2010;68:2320-4. 